\title{
AC 2008-1764: USING A POPULAR TELEVISION SHOW TO EXCITE INTEREST IN SCIENCE AND MATHEMATICS THROUGH ENGINEERING: NUMB3RS FOR TEACHERS
}

Catherine Skokan, Colorado School of Mines

Michael Ewing, Colorado School of Mines

Barbara Moskal, Colorado School of Mines

Heidi Barker, Regis University 


\title{
Using a Popular Television Show to Excite Interest in Science and Mathematics through Engineering: NUMB3RS for Teachers
}

\begin{abstract}
$\underline{\text { Abstract }}$
As part of a continuing effort to increase the mathematical and scientific literacy of middle school teachers and their students, the Colorado School of Mines has offered a series of summer workshops. The theme of these workshops is using engineering concepts to excite teachers' and students' interests in the applications of mathematics and physical science. Each workshop is followed by an academic year intervention during which a graduate student visits the middle school classroom and assists the participating teachers in implementing mathematical and scientific experiments. In the summer of 2007, the workshop was based on the television show NUMB3RS, which is well known for its use of mathematics and science to solve criminal cases. As part of the summer workshop, the teachers viewed an episode of NUMB3RS. Then, they learned about the mathematical and scientific concepts discussed in the show and completed hands-on activities that built on these concepts. Multiple choice pre and post tests were administered at the beginning and end of the workshop to measure change in the teachers' mathematical and scientific knowledge. This paper describes the design of the NUMB3RS workshop and outcomes of our assessment efforts.
\end{abstract}

We all use math every day; to predict weather, to tell time, to handle money. Math is more than formulas or equations; it's logic, it's rationality, it's using your mind to solve the biggest mysteries we know ${ }^{1}$.

\section{Introduction}

In the summer of 2006, a graduate student, Michael Ewing, approached several faculty members at the Colorado School of Mines (CSM), who he knew frequently taught summer content workshops for teachers, with an idea. His idea was to use the popular television show, NUMB3RS, to teach mathematical and scientific content to middle school teachers and their students. At this point in time, the faculty members were only minimally familiar with the television program but found the idea to be intriguing.

Further investigation into this show resulted in the recognition that others had already pursued this idea. In particular, Texas Instruments (TI) and the National Council of Teachers of Mathematics (NCTM) have partnered with CBS Broadcasting, Inc. (CBS) to create educational modules associated with the show. CBS further had granted permission to the educational community to tape and show segments of NUMB3RS for classroom use ${ }^{2}$. TI and NCTM had jointly developed lesson plans in conjunction with the television program that illustrate the importance and applicability of mathematics to the real world. Often, these real world applications include applications to engineering. The TI/NCTM lesson plans were designed by teachers and mathematicians to target grades 9 through 12. 
As part of a grant from the Colorado Department of Education (CDE) with support from the No Child Left Behind Act, the Colorado School of Mines (CSM) was already offering summer workshops to middle school mathematics and science teachers. The theme of these workshops was using engineering concepts to excite teachers' and students' interests in the applications of mathematics and physical science. Offering a workshop that focused on the television series NUMB3RS and that used the previously developed curriculum seemed to be a natural extension of these prior efforts. The specific goals of the workshops that were developed as part of the CDE program are as follows:

1. Improve middle school mathematics and science teachers' knowledge of the disciplines that they teach through practical examples of the use of mathematics, science, engineering, and technology.

2. Assist middle school mathematics and science teachers in developing a repertoire of standards based teaching strategies, activities and lesson plans that employ engineering and technology in their mathematics and science classrooms.

3. Provide middle school mathematics and science teachers the opportunity to acquire the designation of "highly qualified" through college course work.

The purpose of this paper is to describe the design and implementation of the NUMB3RS summer workshop, the fourth and final in the series of CDE funded workshops offered to middle school mathematics and science teachers at $\mathrm{CSM}^{3}$. This paper begins with a brief description of the television series, NUMB3RS, followed by a detailed description of the summer workshop and the results of our assessment efforts.

\section{NUMB3RS}

As of 2008, the television show NUMB3RS is in its $4^{\text {th }}$ season and can be viewed at 10:00 PM Eastern Time. $\mathrm{TI}^{4}$ has described the show as follows:

NUMB3RS is a drama about an FBI agent who recruits his mathematical-genius brother to help solve a wide range of challenging crimes in Los Angeles. The two brothers take on the most confounding criminal cases from a very distinctive perspective. Inspired by actual events, the series depicts how the confluence of police work and mathematics provides unexpected revelations and answers to the most perplexing criminal questions. A dedicated FBI agent, Don Eppes couldn't be more different from his younger brother, Charlie Eppes, a brilliant mathematician who since he was little, yearned to impress his big brother. Despite their disparate approaches to life, Don and Charlie are able to combine their areas of expertise and solve serious crimes.

\section{Workshop Design}

The NUMB3RS summer workshop was offered to middle school mathematics and science teachers over a two week period. Each day of the workshop was seven hours long, with a four hour morning and a three hour afternoon session. Both the morning and the afternoon sessions focused on hands-on activities designed to improve the participating teachers' knowledge and understanding of how science, mathematics, 
engineering and technology can be used to enhance science and mathematics instruction. A detailed schedule of the workshop activities is displayed in Table 1.

Teachers were self-selected and drawn from 9 school districts in the Denver Metro area. Thirteen mathematics teachers and 14 science teachers attended this workshop in the summer of 2007. Although the majority of the lessons were selected from the TI/NCTM units, changes were necessary. The original lesson plans were developed for grades 9 through 12; our teachers were instructing grades 6 through 8 . Therefore, many concepts and episodes were inappropriate for the given grade range. All episodes were viewed by graduate students for the purpose of evaluating content and episode appropriateness. Inappropriate lessons were either redesigned or not used; inappropriate episodes were either not viewed or only partially viewed with inappropriate components removed. The second change was the augmentation of the lessons to included engineering applications. To illustrate our approach, two episodes and their associated lesson plans are discussed here, "Structural Corruption" and "Obsession".

\section{"Structural Corruption"}

At the start of this episode, an engineering student commits suicide. Charlie believes the student was murdered because of the findings of his research thesis concerning the structural integrity of a building. Don does not agree that a crime has been committed but does agree to allow Charlie to investigate.

The TI/NCTM lesson plan was designed to examine pendulums and Foucault's pendulum using conic sections and the graphing calculator. In our workshop, the mathematics teachers investigated conic sections, parabolas and projectile motion using the graphing calculator. The science teachers discussed wave motion, deflection, inertia, and damping and how these topics inform the structural design of tall buildings. In the afternoon, the mathematics and science teachers jointly investigated the use of computer simulations, such as the physics simulator ${ }^{5}$ and the earthquake simulator ${ }^{6}$, and vibration analysis in the design of tall buildings, providing exposure to the concepts and tools used by civil, mechanical, and architectural engineers

\section{"Obsession"}

In this episode, a popular singer is threatened by an intruder at her home and by a series of letters. Charlie is called in as a consultant to the case and determines that the letters were written by two people. When another person is found dead near the singer's home, Don concludes that the incidents are related.

The TI/NCTM lessons address a variety of mathematical and scientific topics, including hand-writing analysis, trigonometry, lenses, the human eye, and spherical astronomy. After viewing this lesson, the participating mathematics teachers reviewed polygons and angles, and used these concepts to complete an exercise concerning the minimum number of guards needed to secure an art gallery with specified dimensions. The science teachers studied lenses and the human eye. Jointly, the mathematics and science teachers applied these skills by constructing a sun dial and analyzed hand-writing samples. 
Table 1: Summer Workshop - The Math and Science of NUMB3RS

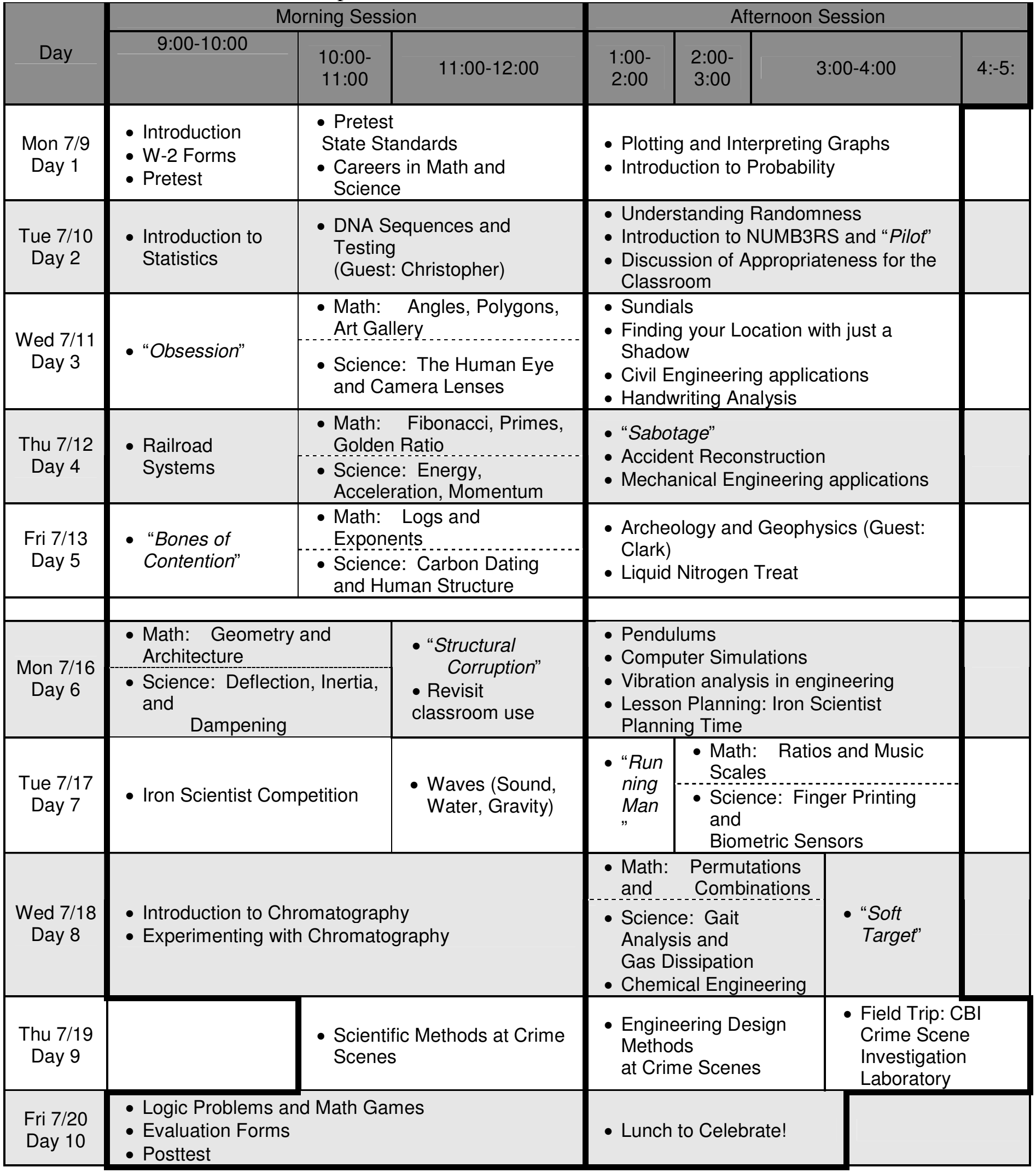




\section{Academic Year Follow-up}

The first phase of this program was the implementation of the summer workshop. The second phase occurred during the academic year. Throughout the academic year, a CSM graduate student visited each of the participating teachers on a weekly basis and provided assistance as the teachers implemented hands-on activities in the classroom. Half of the teachers chose to participate in this follow-up. These visits served multiple purposes. For the teachers, they provided encouragement to utilize the physical science, mathematics, and engineering content covered during the workshop and an additional set of hands to implement these activities in the classroom. They also provided "resident experts" in the classroom who may be used to answer questions both from the teachers and students. For the students, the graduate students acted as near-peer role models and provided an interactive and engaging learning environment that connects engineering to real world applications.

\section{Assessment Methods}

Both formative and summative evaluations were used throughout this program. Since formative evaluations are designed for program improvement rather than for the measurement of the attainment of project goals, this paper presents only the results of our summative efforts.

Four methods of summative assessment were used. First, a 27 question, multiple-choice test was developed for each content area, i.e., mathematics or science, by the project investigators in collaboration with the project evaluator. One instrument was developed for the mathematics teachers and one for the science teachers. The appropriate content test was administered on the first (pre) and last (post) day of the workshop. The items that comprised the pre and posttest for a given content area were identical. To ensure content and construct validity, the project investigators acted as content experts and constructed a preliminary set of assessment items. The external evaluator reviewed these items and provided feedback for revision purposes based on the psychometric principles of validity and reliability. Paired t-tests were used to examine whether this measurement reflected a statistically significant difference in the participating teachers' content knowledge from beginning to end of the workshop.

Second, a self-report survey was administered to teachers at the end of the summer workshop. This instrument was developed by the institution as a common feedback form used across summer courses. Neither the investigators nor the evaluator influenced the questions that were included on this survey. The third form of assessment was a followup survey which was administered to the participating teachers at the end of the fall semester during a project meeting. The final form of assessment was the examination of the teachers' advancement toward acquiring the designation of "highly qualified" in their content area.

\section{Assessment Results}

The mean score on the mathematics pretest was 14.6 out 27 with a range of 11 to 19 . The mean score on the workshop mathematics posttest was 20.1 out of 27 with a range of 13 
to 26. All participating mathematics teachers increased their scores from pre to posttest. Based on a paired t-test, there was a statistically significant improvement in performance on the mathematics test from pre to posttest $(n=13 ; \mathrm{p}=0.000)$. All mathematics teachers participated in this evaluation.

The mean score on the science pretest was 15.3 out 27 with a range of 10 to 21 . The mean score on the science posttest was 18.7 out of 27 with a range of 16 to 22 . One science teacher had the same score on the pre and the posttest. The remaining teachers $(n=12)$ all displayed an increase. Based on a paired t-test, this indicates a statistical significant improvement from pre to posttest $(n=14 ; p=0.000)$. All science teachers participated in this evaluation.

The second method of evaluation was the end of the workshop teacher self-report survey. All teachers, both mathematics and science, reported that they valued the hands-on activities and expected to use these activities their classroom. In response to follow-up survey which was administered at the end of the fall semester, all teachers reported that they had used or have scheduled to use workshop activities in their classrooms. Additionally, all of the participating teachers received five graduate-level continuing education credits which may be applied to "highly qualified" status.

\section{Conclusions}

These results support that the first two goals of the project have been met. The participating teachers did display an increase in their discipline specific knowledge as was reflected through the pre and posttest results. Additionally, the teachers did report using the workshop activities in their classrooms. The third goal concerned the attainment of "highly qualified" status in their content areas. Through the awarding of continuing education credits, all of the participating teachers advanced in this area.

In the development of the summer workshop, there were several challenges that should be noted. Some of the content and many of the episodes were inappropriate for a middle school audience. Therefore, the selection of episodes was done with great care. For example, the question of suicide as an appropriate topic for middle school students was addressed by the participating teachers. Another concern is the manner in which the female mathematician is portrayed in the series. According to Silverberg ${ }^{7}$, a mathematics consultant for the show, the only female mathematician in the show is portrayed as a "sex object" rather than as a content expert. Greenwald ${ }^{8}$ warns, "the mathematical ideas the TV show raises come freighted with the program's violence, sexual innuendos, and somewhat stereotypical view of mathematicians." Silverberg also warns that the mathematics is sometimes forced into a plot when there is no natural fit. To address these and other concerns, regular discussions were held at the workshop participants concerning the classroom appropriateness of the individual episodes. Additionally, the teachers were provided with software containing the episodes so that they could extract scenes and remove unsuitable material prior to classroom viewing. 


\section{Future Directions}

Through a combination of funding from the National Science Foundation, Colorado Commission on Higher Education and the Colorado Department of Education, seventeen workshops have been offered over the last five years to a mix of teachers in the Denver Metro area and on the Western Slope of Colorado. Based on our assessment results ${ }^{9}$, these efforts have been highly effective for improving teachers' content and pedagogical knowledge. Many teachers, however, select not to complete these workshops because of the two-week in-class summer requirement. These teachers often have summer childcare responsibilities or summer employment. By reducing the in-class requirement to one week, expert teachers within the districts have assured us that the majority of teachers will be able to participate. This is based on the following: 1) one week of child care as opposed to two weeks significantly decreases the financial burden, and 2) many summer jobs provide for a one week vacation. Therefore, NUMB3RS for Mathematics and Science Teachers has been converted to a hybrid version with one week offered on-line and the second week offered in a traditional classroom. The online component provides flexibility in terms of when the teachers can complete the first week of material, which includes viewing the selected episodes. The second week will be classroom based and will consist of activities that illustrate how the on-line instruction can be delivered to students through hands-on activities. The second week will also provide for discussions with the teachers concerning the connections to mathematics, science, and engineering as well as the appropriateness of the material and episodes. A future study will compare the effectiveness of the two-week classroom workshop with the hybrid version.

\section{Bibliography}

1. Numb3rs, http://en.wikipedia.org/wiki/Numb3rs, accessed 1/08

2. http://www.weallusematheveryday.com/tools/files/waumed_taping_terms.pdf, accessed 1/08

3. Moskal, Barbara, Skokan, C., Kosbar, L., Dean, A., Westland, C., Barker, H., Nguyen, Q., and Tafoya, J., 2007, K-12 Outreach: Identifying the Broader Impacts of Four Outreach Projects: JEE, Vol. 96, No. 3

4. NUMB3RS: We All Use Math Every Day, http://education.ti.com/educationportal/sites/UK/nonProductSingle/numb3rs.html, accessed 1/08

5. TLC: "Make a Quake", http://tlc.discovery.com/convergence/quakes/interactives/makeaquake.html, accessed 1/08

6. My Physics Lab, http://www.myphysicslab.com/, accessed 1/08

7. Silverberg, Alice, 2006, Alice in Numb3rland, FOCUS, Math. Assn. Am., Vol. 26, No. 8

8. Greenwald, Sara, 2007, Is NUMB3RS Good for Math Teaching?, Am. Math. Soc., http://www.weallusematheveryday.com/tools/waumed/home.htm

9. Moskal, Barbara, Skokan, C., Kosbar,L., Dean, A., Westland, C., Barker, H., Nguyen, Q. and Tafoya, J., 2007, K-12 Outreach: Identifying the Broader Impacts of Four Outreach Projects: JEE, Vol. 96, No. 3 . 